\title{
The Mediating Role of the Emotional Intelligence in the Organizational Justice and Contextual Performance Relationship of Administrative Staff in Pakistan
}

\author{
Hazrat Bilal * $\quad$ Shahid Ali ${ }^{\dagger} \quad$ Naveed Ali $\ddagger \quad$ Lala Rukh $\S$
}

\begin{abstract}
The purpose of this article was to examine a model that recognizes the effect of organizational justice on contextual performance. The model also assessed the mediating role of emotional intelligence in the connection of organizational justice and contextual performance. The data were gathered from 202 self-administered questionnaires, sampling respondents from administrative staff working in private sector universities. The relationships among these variables were examined by the use of Pearson correlation and Regression PROCESS V3.3 statistical tools. The findings of the study confirmed that correlation exists among organization justice, emotional intelligence, and contextual performance. The study also confirmed that organizational justice is the best prognosticator of contextual performance. Furthermore, it was also concluded that emotional intelligence entirely mediates the connection between organizational justices and contextual performance. These models have provided important understandings to the existing literature and have implications for both academicians and practitioners.
\end{abstract}

Keywords: Organizational Justice, Emotional Intelligence, Contextual Performance, Mediating role of Emotional Intelligence, Private Sector University.

\section{Introduction}

The Organizational Justice (OJ) is one of the most popular organizational factors in the context of job performance models investigated to date (Devonish \& Greenidge, 2010). OJ is the portrayal of fairness at work. According to Equity theory of Adams (1965), an individual experiencing inequity or injustice will try to restore equilibrium using a number of mechanisms, including reduction in efficiency and withdrawn physically and emotionally. A great deal of studies has supported the fact that one main result of perceptions of OJ is performance (Colquitt, 2001; Nowakowski \& Conlon, 2005), and is the best predictor of contextual performance. Contextual performance is the employees' voluntary, positive work behaviour that goes beyond the job description and can be effected by other variables too such as employee engagement, performance appraisal and motivation. However, in

\footnotetext{
* Centre for Management and Commerce, University of Swat, Khyber Pakhtunkhwa, Pakistan.

†'Department of Economics \& Development Studies, University of Swat, Khyber Pakhtunkhwa, Pakistan.

$\ddagger$ Institute of Economics and Development Studies, University of Swat, Khyber Pakhtunkhwa, Pakistan.

$\S$ Center for Management and Commerce, University of Swat, Khyber Pakhtunkhwa, Pakistan.
} 
organizational settings there is comparatively very little research available on the prediction of OJ and CP. Emotional intelligence is the ability to motivate and cultivate emotions, in relation to one's own feelings and the feelings of others (Hakim \& Pristika, 2020; Serrat, 2017).

Previous research has received little attention so far on the mediating effect of Emotional Intelligence (EI) on the relationship between OJ and CP. Many critics observed that further study needs to look at the role of different factors played in the link between OJ and performance (Devonish \& Greenidge, 2010). Therefore, this study aims at replicating and validating earlier findings of different countries, industry and research models concerning connections between OJ and CP. Moreover, it examines the effect of perceived EI as a mediator on the connection between OJ and CP.

\section{Objectives and Significance of the Study}

The first objective of this research is to assess the effect of OJ on CP in administrative staff of private sector universities of Khyber Pakhtunkhwa, Pakistan. The second objective is to analyse the mediating effect of EI on the relationship of OJ and CP. The significance of this research is to test the prevailing Social Exchange Theory (SET) of Blau (1968). According to Greenberg and Colquitt (2013), OJ is developed on the basis of SET, which concentrates on employees' convictions to receive a fair share of significant organizational achievements such as pay incentives, appreciation (Harris, 2014).

\section{Literature Review}

\section{Contextual Performance}

Contextual performance refers to those discretionary activities of employees which make a significant contribution to the organization's social and psychological core such as going above and beyond the duties incorporated in their job description (Motowildo, Borman, \& Schmit, 1997). Such employees have voluntary efforts, spontaneous and extra-role behaviour, which plays an important role in achieving organizational competitive advantage effectively and efficiently. Motowildo et al. (1997); Organ (1988), describe that CP encompasses both organizational citizenship behaviour and prosaically behaviour characteristics. It continues with enthusiasm for the additional efforts necessary to accomplish one's own task successfully. It is a volunteering owns self-involvement for the conduct and exercise of tasks that are not formally included in one's own job description and helps, cooperates with others, and follow properly organizational rules and procedures in completing tasks. According to Goodman and Svyantek (1999), CP is less role described and include actions like volunteering one's self to carry out tasks which are not formally integral part of the job description such as helping others, following organization's rules and procedures even when they are personally disadvantageous, approving and promoting organizational goals, and continuing to work hard to carry out the organizational objectives effectively. 


\section{Organizational Justice}

The term OJ, which assesse the behaviour of the organization and the resulting employee attitudes, was first introduced by Greenberg and Tyler (1987) which refers to how fair the workplace procedures, interactions and results are perceived by employees. Such perception can have a constructive or adverse effect on employee performance and organizational success in terms of behaviour for good or ill (Baldwin, 2006). Specifically, OJ deals with how employees decide whether they are treated fairly in their work and how these determinations influence other work-related factors. It also helps to explain why employees take action against inadequate outcomes or inadequate interactions and processes, which benefit both the organization and its employees and thus describes the perception and behavioural response of the people (or groups) about fair treatment received from an organization (Iqbal, 2017).

Organizational justice can be studied from three important aspects. The first aspect is the Distributive Justice, that relates to the fairness of the decision concerning resources allocation within an organization, and input-responsive results - the so-called principles of equity (Adams, 1963). Employees compare their input and output with those of others in order to evaluate the fairness of the results. The outcome in a work context may take the form of financial and nonofficial resource like wages, salary, promotion, praise, job security, trainings and rewards. Distributive justice is deemed to be achieved when employees are made aware that their efforts and rewards are equally assessed (Yean et al., 2016). The second facet is the Procedural justice, which means fair procedures for the processes and methods that have been implemented to the extent that such results were achieved, as well as how the final decisions were taken. Procedural justice refers to satisfaction as a function of the process, which is the step that management takes to reach a fair decision (Colquitt, 2001). Where organizational processes and practices are seen as fair, the participants will be more satisfied, willing to accept resolution, and more likely to develop positive attitudes to the organization (Folger \& Cropanzano, 1998). The third feature is the Interactional justice, that is particularly concerned with the quality of human interpersonal treatment working within an organization as part of the formal decision-making procedure and is a fair treatment received by an employee following management decisions. Interactional justice one aspect is interpersonal justice which involves various socially sensitive actions, such as treating employees with respect and dignity by supervisors. Therefore, it is the employees ' perception that they are treated with kindness and respect. The other aspect of the interaction justice is the informational justice, which refers that an employer willingly provides and share timely, realistic, accurate, and sufficient information and explanation in open and fortnightly manner to its employees (Folger \& Cropanzano, 1998). If the truthfulness and justification of information conveyed to employees is not adequate or inaccurate will lead to injustice (Bies, 2001).

\section{Emotional Intelligence}

There are many arguments about the definition of EI. As the field grows so rapidly, researchers are constantly modifying their own definitions (Schulze \& Roberts, 2005). The concept of EI was introduced by psychologists as the ability to understand access to and 
produce emotions to aid thinking, recognise emotions and knowledge, and contemplatively regulate emotions to encourage emotional and intellectual growth (Mayer, Salovey, \& Caruso, 2000). It is the ability of a person to recognize his own and others feelings, for discerning between different feelings and labelling them appropriately, for using emotional information to guide thinking and behaviour. In terms of personal achievement, career success, leadership, and living satisfaction, Low, Nelson, et al. (2006) say the most important variable is EI. They believe that a person who is emotionally fit can identify, learn and experience human emotions in a healthy and productive way.

The benefits of EI are better relationships with people, communication with others, improved empathy, integrity, a better respect for others, a better career outlook, a more secure way to manage change, and a good attitude towards the work (Sternberg, Ruzgis, et al., 1994). According to Mayer, Salovey, and Caruso (2004) EI includes the ability to properly perceive feelings, access them and create feelings to assist think, comprehend feelings and emotional knowledge. It is a pure form of mental ability and therefore a pure intelligence and is identified as the ability model of EI (MacCann et al., 2020; Salovey \& Mayer, 1990).

Relationship among Organizational Justice, Contextual Performance and Emotional Intelligence Because of the casual relationship between OJ and performance, the notion of OJ receives significant attention from both practitioners and academicians to solve the human behavior associated problems in an organization. Despite the acceptance of the concept of OJ and its applications nationally and internationally, the concept of OJ in organizations, specifically in Pakistan, is remarkably lacking in empirical studies. The literature reveals that there have been only a few studies that examine the mediating role of EI (Johnson, Batey, \& Holdsworth, 2009; Lanciano, Curci, Kafetsios, Elia, \& Zammuner, 2012; Ling, Raine, Gao, \& Schug, 2018), but none of the studies have investigated EI mediating effect on OJ - CP relationship. It identifies a major gap in literature research regarding the significant role played by EI in the administrative staff of private owned universities. In light of the previous studies the present study tries to address the research gap by identifying the effect of OJ on CP in the presence of mediation effect of EI. In this respect, the ultimate hypotheses in the present research are:

$H_{1}$ : OJ is significantly associated to contextual performance.

$\mathrm{H}_{2}$ : $\mathrm{OJ}$ is significantly associated to Emotional Intelligence.

$H_{3}$ : EI is significantly related to Contextual performance in the presence of Organizational Justice.

$H_{4}$ : EI fully mediates the association between Organizational Justice and Contextual Performance. 


\section{Figure 1}

Theoretical Model

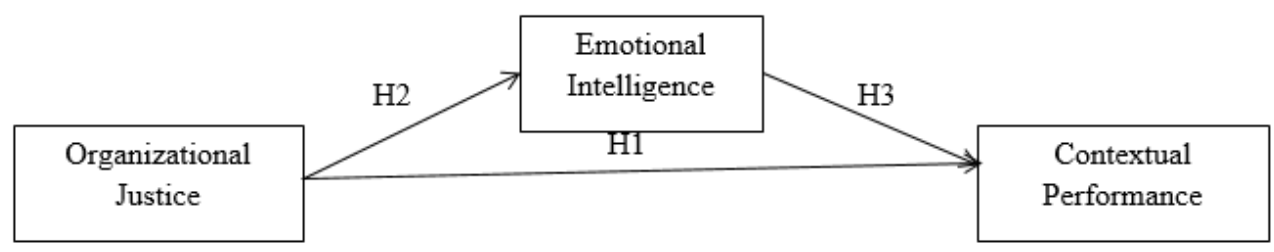

\section{Methodology}

\section{Participants}

Data were collected using the self-administered questionnaire and a cover letter indicating the drive of the study. A total of 230 questions were distributed, 216 of them were returned; out of which 14 questionnaires containing more than $45 \%$ missing data, and hence they were excluded from further analysis. A total usable questionnaire were become 202 with a $87.8 \%$ response rate. The questionnaire encompasses EI, OJ, CP and demographic information such as qualification, age, gender, marital status, experience, and level of management. The participants of the study were the administrative staff working in private sector universities of Khyber Pakhtunkhwa.

\section{Population and Sample}

In order to make the sample representative of the population, a simple random samples approach was used because of the impaired random selection of participants (Patten \& Newhart, 2017). In the course of multivariate statistical analysis (Avkiran, 1994) advises that sample size should be between 200-500 samples. A sample of 230 administrative staff was obtained, which was considered appropriate. Employees with at least 1 year of working experience were eligible for the study.

\section{Statistical Analysis}

The data was analysed through SPSS version 21 and due to the nature of the quantitative data, both descriptive and inferential statistical methods were used for data analysis and testing of hypotheses.

\section{Measurements}

The OJ was assessed by a 20-items adopted scale of Niehoff and Moorman (1993). The EI was measured by a 33-items adopted scale of Schutte et al. (1998) and the CP was evaluated by a 9-items adopted scale of Goodman and Svyantek (1999). All these scale 
were appraised on a 5 point Likert rating scale, ranging from 1 strongly disagree to 5 strongly agree.

\section{Demographic Profile}

The demographic profile of the participants was presented in Table 1. The sample was comprises of $78.2 \%$ male out of which 73.8 and $21.8 \%$ female, $73.8 \%$ were married and $26.2 \%$ single. $48.5 \%$ respondents were having post-graduation, with an average age of 34 years $(\mathrm{SD}=1.86)$, average experience with the university was 11.5 years and $(\mathrm{SD}=1.05)$. The $50.5 \%$ of the respondents were working at lower level (Junior Clerks, Senior Clerks, Computer Operators, Superintendents, and Assistants), 33.7\% respondents were at middle level management (Coordinator, Deputy, Head of Department), the top level management of our respondents was comprises of $15.8 \%$ (Director, Registrar, Controller, Treasurer).

\begin{tabular}{|c|c|c|c|}
\hline Variable & Std. Dev & Frequency & $\%$ \\
\hline Sex & 0.414 & & \\
\hline Masculine & & 158 & 78.2 \\
\hline Feminine & & 44 & 21.8 \\
\hline Marital Status & 0.441 & & \\
\hline Wedded & & 149 & 73.8 \\
\hline Single & & 53 & 26.2 \\
\hline Age & 1.86 & & \\
\hline 25 or Below & & 16 & 7.9 \\
\hline 26 to 30 & & 80 & 39.6 \\
\hline 31 to 35 & & 48 & 23.8 \\
\hline 36 to 40 & & 30 & 14.9 \\
\hline 41 and Above & & 28 & 13.9 \\
\hline Education & 0.88 & & \\
\hline Graduation & & 34 & 16.8 \\
\hline Post-Graduation & & 98 & 48.5 \\
\hline MS/MPhil & & 47 & 23.3 \\
\hline $\mathrm{PhD}$ & & 23 & 11.4 \\
\hline Experience & 1.05 & & \\
\hline One to five years & & 53 & 26.2 \\
\hline Six to ten years & & 62 & 30.7 \\
\hline Eleven to fourteen years & & 61 & 30.2 \\
\hline Fifteen to Nineteen years & & 21 & 10.4 \\
\hline Twenty to Twenty five years & & 5 & 2.5 \\
\hline Level of Management & 0.739 & & \\
\hline Upper Level & & 32 & 15.8 \\
\hline Middle Level & & 68 & 33.7 \\
\hline Lower Level & & 102 & 50.5 \\
\hline
\end{tabular}

\section{Emotional Intelligence, Contextual Performance and Organizational Justice}

The statistical analysis results of Mean and Standard deviation of the dimension of variables and reliability statistics based on Cronbach's alpha coefficient are demonstrated in Table 2. The participants had a moderate level of EI with a mean 2.38 value $(\mathrm{SD}=1.15)$. For components of EI the mean value of $\mathrm{SEA}=3.05(\mathrm{SD}=.873)$, Mean value of $\mathrm{OEA}=2.87$ $(\mathrm{SD}=.704)$, Mean value of $\mathrm{UOE}=3.05(\mathrm{SD}=.668)$, Mean value of $\mathrm{ROE}=3.16(\mathrm{SD}=$ 
.750). The mean and standard deviation of $\mathrm{CP}$ was recorded $2.05(\mathrm{SD}=1.04)$. The overall OJ score were having a meaning value of $2.08(\mathrm{SD}=1.04)$. Among the four dimensions of OJ, CP have the lowest mean $=2.05(\mathrm{SD}=1.04)$, and FPJ have the highest mean of $2.98(\mathrm{SD}=.595)$, followed by DSTJ mean value of $2.87(\mathrm{SD}=.575)$ and ITJ mean score of $2.23(\mathrm{SD}=.491)$. An alpha 0.7 is commonly accepted as a thumb rule and 0.8 or higher indicates a good reliability (Nunnally, 1994). For all the scales of our study, the alpha reliability coefficient fell within the acceptable range of 0.78 and 0.93 .

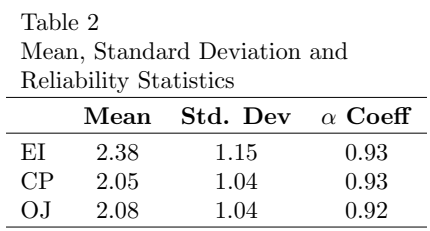

\section{Correlational Analysis}

The Pearson correlational analyses of all three variables are depicted in Table 3. The EI, $\mathrm{CP}$ and OJ were positively correlated with each other. Statistically significant correlations were revealed between EI and CP $(\mathrm{r}=.433, \mathrm{p}<0.01)$, EI and OJ $(\mathrm{r}=.551, \mathrm{p}<0.01)$ and $\mathrm{CP}$ and $\mathrm{OJ}(\mathrm{r}=.224, \mathrm{p}<0.01)$.

\begin{tabular}{|c|c|c|c|}
\hline Variable & EI & CP & OJ \\
\hline EI & 1 & & \\
\hline $\mathrm{CP}$ & $.433^{* *}$ & 1 & \\
\hline OJ & $.551^{* *}$ & $.244^{* *}$ & 1 \\
\hline
\end{tabular}

\section{Mediation Analysis}

Mediation analysis was carried out using the PROCESS bootstrap methodology developed by (Hayes \& Scharkow, 2013). According to Memon et al. (2018), the Preacher and Hayes (2004) mediation process is usually the standard procedure and methodology for evaluating hypotheses to clarify the mediation and casual relationship among variables. The results of Preacher and Hayes (2004) mediation Process are shown in Table 4. The step 1 in the Table 4 indicates $\mathrm{R} 2=0.059$, which specifies a total variation of $5.9 \%$ in $\mathrm{CP}$ can be explained by OJ with a $\mathrm{p}<0.001, \mathrm{~F}=12.639$. The coefficient of OJ is 0.338 predicts that a one unit increase in OJ predicts a .338 units increase in CP. Thus OJ contribute significantly to the model with $\mathrm{t}=3.55, \mathrm{p}=0.000$. As $5.9 \%$ variation is very small but it is significant. Step 2 in the Table 3 shows $\mathrm{R} 2=0.302$, which predicts a total variation of $30.2 \%$ in the EI with a $\mathrm{p}<0.001, \mathrm{~F}=86.634, \mathrm{t}=9.307$ and Coefficient $=.836$ for OJ. It shows that a one unit increase in OJ predicts a 0.302 unit increase in EI. Step 3 confirms a significant connection between mediator and dependent variable with Coefficient $=.390$, $\mathrm{t}=5.584 \mathrm{p}<0.001$ and $\mathrm{F}=86.634$ and therefore, we accepted our third hypothesis. Step 
4 in the Table 4 depicts the effect of OJ through direct effect on CP, and indirect effect on $\mathrm{CP}$ via EI. The total effect of this direct and indirect effect of OJ was recorded 0.338 on CP. When EI was included in the model, the direct effect of OJ on CP was calculated as .0123 with a positive sign which implies that the relationship between OJ and CP is positive. The indirect effect was measured to determine that how much of the effect of OJ on CP has been mediated. The result of indirect mediation effect was recorded 0.326 , which is significance without a zero value between the confidence interval upper and lower boot values.

Table 4

Mediation Analysis Using Process F. Hayes (2018) Macros in SPSS 21

\begin{tabular}{|c|c|c|c|c|c|c|c|}
\hline & $\begin{array}{l}\text { Model : } 4 \\
\text { Y : CP } \\
\text { X : OJ } \\
\text { M : EI Sample Size: } 202\end{array}$ & & & & & & \\
\hline & Model Summary & & & & Outcome & Variable: & CP \\
\hline & $\mathbf{R}$ & R-sq & MSE & $\mathbf{F}$ & Df1 & Df2 & p \\
\hline & 0.244 & 0.059 & 0.303 & 12.639 & 1 & 200 & 0.0005 \\
\hline \multirow[t]{7}{*}{ Step 1} & Model & & & & & & \\
\hline & & Coeff & SE & $\mathbf{t}$ & $\mathbf{p}$ & LLCI & ULCI \\
\hline & Constant & 2.885 & 0.331 & 8.714 & 0 & 2.233 & 3.538 \\
\hline & OJ & 0.338 & 0.0953 & 3.555 & 0.0005 & 0.1509 & 0.526 \\
\hline & Model Summary & & & & Outcome & Variable: & : EI \\
\hline & $\mathbf{R}$ & R-sq & MSE & F & Df1 & Df2 & $\mathbf{P}$ \\
\hline & 0.551 & 0.302 & 0.269 & 86.634 & 1 & 200 & 0 \\
\hline \multirow[t]{7}{*}{ Step 2} & Model & & & & & & \\
\hline & & Coeff & $\mathrm{Se}$ & $\mathbf{t}$ & $\mathrm{p}$ & LLCI & ULCI \\
\hline & Constant & 1.146 & 0.312 & 3.671 & 0.0003 & 0.53 & 1.762 \\
\hline & OJ & 0.836 & 0.089 & 9.307 & 0 & 0.659 & 1.014 \\
\hline & Model Summary & & & & Outcome & Variable: & CP \\
\hline & $\mathbf{R}$ & R-sq & MSE & $\mathbf{F}$ & Df1 & Df2 & p \\
\hline & 0.433 & 0.187 & 0.2633 & 22.86 & 2 & 199 & 0 \\
\hline \multirow[t]{9}{*}{ Step 3} & Model & & & & & & \\
\hline & & Coeff & SE & $\mathbf{t}$ & $\mathbf{p}$ & LLCI & ULCI \\
\hline & Constant & 2.44 & 0.319 & 7.645 & 0 & 1.809 & 3.067 \\
\hline & OJ & 0.012 & 0.101 & 0.111 & 0.908 & -0.197 & 0.222 \\
\hline & EI & 0.39 & 0.069 & 5.584 & 0 & 0.253 & 0.528 \\
\hline & Total effect of $\mathrm{X}$ on $\mathrm{Y}$ & & & & & & \\
\hline & & Effect & SE & $\mathbf{t}$ & $\mathbf{p}$ & LLCI & ULCI \\
\hline & & 0.338 & 0.0953 & 3.555 & 0.0005 & 0.526 & 0.598 \\
\hline & Direct effect of $X$ on $Y$ & & & & & & \\
\hline \multirow[t]{5}{*}{ Step 4} & & Effect & SE & $\mathbf{t}$ & $\mathbf{p}$ & LLCI & ULCI \\
\hline & & 0.0123 & 0.1016 & 0.111 & 0.907 & -0.197 & 0.222 \\
\hline & Indirect effect(s) of $\mathrm{X}$ on $\mathrm{Y}$ : & & & & & & \\
\hline & & Effect & BootSE & BootLLCI & BootULCI & & \\
\hline & EI & 0.326 & 0.093 & 0.153 & 0.516 & & \\
\hline
\end{tabular}

Confidence level for all output confidence intervals: 95.0000

Number of bootstrap samples for percentile bootstrap confidence intervals: 5000

\section{Discussion}

The current research led to the fact that OJ significantly linked with CP. In the step 1 of the given mediation model, the regression of OJ with the $\mathrm{CP}$ was significant at $\mathrm{b}=.338$, $\mathrm{t}=3.55, \mathrm{p}<.001$. These Findings are compatible with previous studies conducted on the OJ and CP relationship (Larbi, 2014; Lind, Kanfer, \& Earley, 1990). This research also 
showed in step 2, that high levels of OJ are significantly linked with high levels of EI (b $=.836, \mathrm{t}=9.307, \mathrm{p}<.001)$. The findings are in line with the preliminary studies being carried out on such connection between OJ and EI (Di Fabio \& Palazzeschi, 2012; Ouyang, Sang, Li, \& Peng, 2015). The key purpose of this research was to assess the mediating effects of EI on the relationship of OJ and CP. The results thereby demonstrated a link between OJ, EI and CP. Step 3 of the mediation model revealed that the mediator EI, relationship with $\mathrm{CP}$ in the presence of OJ was significant $\mathrm{b}=.390, \mathrm{t}=5.584, \mathrm{p}<.001$. Step 4 showed that EI fully mediates the association between OJ and CP.

\section{Implications}

From theoretical point of view, this study contributes to the literature in the form of investigating into the mediating role of EI on the relationship of OJ and CP (Conlon, Meyer, \& Nowakowski, 2005), employees who think they've been treated with a high standing of OJ often improve performance. The present research showed that perceived EI mediates the connection between OJ and CP, which promotes our understanding of how OJ impacts on work outcomes in the presence of EI. In practical terms, this study offers solid reasons for OJ implementers in the organization, as it empirically demonstrate significant positive relationship among $\mathrm{OJ}, \mathrm{EI}$ and $\mathrm{CP}$ of University sector administrative employees. OJ is critical in service oriented organizations for efficient performance all over the world. The presence of positive relations between OJ and CP is likely to increase the overall performance of employees through employing people with high EI; therefore, this research provides organizations with better decision-making assistance in their policy making and human resource activities.

\section{Limitations}

This research contained a number of limitations. The sample was small covering one province of Pakistan and was based on employee's self-reported perception. The questionnaire was taken irrespective of order effect, which could have artificially inflated the relationships between variables. This study was cross sectional study, in future studies shall be conducted with a transnational sample on both longitudinal and cross sectional methods. Further research shall also be needed on this mediating model in a wider general population sample indigenously and internationally using more objective measures of performance measures within various cultures.

\section{Conclusion}

In the field of human resource management and organizational behaviour, there has been very little research on the OJ, ET and CP association in Pakistan. No empirical evidences have been found from service sector such as Universities to analyse the mediating effect of EI on the relationship of these dependent and independent variables. This is a unique study being conducted in developing countries like Pakistan and hence based on results of our analysis we have accepted our all four hypothesis. 


\section{References}

Adams, J. S. (1963). Towards an understanding of inequity. The Journal of Abnormal and Social Psychology, 67(5), 422.

Adams, J. S. (1965). Inequity in social exchange. In Advances in experimental social psychology (Vol. 2, pp. 267-299). Elsevier.

Avkiran, N. K. (1994). Developing an instrument to measure customer service quality in branch banking. International Journal of Bank Marketing.

Baldwin, S. (2006). Organisational justice. Institute for Employment Studies Brighton.

Bies, R. J. (2001). Interactional (injustice: The sacred and the profane. in j. greenberg $\&$ r. cropanzano (eds.), advances in organizational justice (pp. 89-118). Stanford, CA: Stanford University Press.

Blau, P. M. (1968). Social exchange. International Encyclopedia of the Social Sciences, 7, 452-457.

Colquitt, J. A. (2001). On the dimensionality of organizational justice: A construct validation of a measure. Journal of Applied Psychology, 86(3), 386-400.

Conlon, D. E., Meyer, C. J., \& Nowakowski, J. M. (2005). How does organizational justice affect performance, withdrawal, and counterproductive behavior?

Devonish, D., \& Greenidge, D. (2010). The effect of organizational justice on contextual performance, counterproductive work behaviors, and task performance: Investigating the moderating role of ability-based emotional intelligence. International Journal of Selection and Assessment, 18(1), 75-86.

Di Fabio, A., \& Palazzeschi, L. (2012). Organizational justice: Personality traits or emotional intelligence? An empirical study in an Italian hospital context. Journal of Employment Counseling, 49(1), 31-42.

Folger, R. G., \& Cropanzano, R. (1998). Organizational justice and human resource management (Vol. 7). Sage.

Goodman, S. A., \& Svyantek, D. J. (1999). Person-organization fit and contextual performance: Do shared values matter. Journal of Vocational Behavior, 55 (2), 254-275.

Greenberg, J., \& Colquitt, J. A. (2013). Handbook of organizational justice. Psychology Press.

Greenberg, J., \& Tyler, T. R. (1987). Why procedural justice in organizations? Social Justice Research, 1(2), 127-142.

Hakim, A., \& Pristika, A. (2020). The influence of organizational citizenship behavior, continuance commitment, emotional intelligence, and spirituality on performance. In 17th International Symposium on Management (INSYMA 2020) (pp. 80-84).

Harris, T. C. (2014). Organizational justice: A primer. Bridgewater Review, 33(1), 4-7.

Hayes, A. F., \& Scharkow, M. (2013). The relative trustworthiness of inferential tests of the indirect effect in statistical mediation analysis: Does method really matter? Psychological Science, 24 (10), 1918-1927.

Iqbal, M. Z. (2017). The impact of organizational justice on employee performance in public sector organization of Pakistan. International Journal of Economics $\&$ Management Sciences, 6(3). doi: 10.4172/2162-6359.1000431 
Johnson, S. J., Batey, M., \& Holdsworth, L. (2009). Personality and health: The mediating role of trait emotional intelligence and work locus of control. Personality and Individual Differences, 47(5), 470-475.

Lanciano, T., Curci, A., Kafetsios, K., Elia, L., \& Zammuner, V. L. (2012). Attachment and dysfunctional rumination: The mediating role of emotional intelligence abilities. Personality and Individual Differences, 53(6), 753-758.

Larbi, R. (2014). Relationship between organizational trust, organizational justice and contextual performance at electricity company of Ghana in Accra (Unpublished doctoral dissertation). University of Ghana.

Lind, E. A., Kanfer, R., \& Earley, P. C. (1990). Voice, control, and procedural justice: Instrumental and noninstrumental concerns in fairness judgments. Journal of Personality and Social Psychology, 59(5), 952-959.

Ling, S., Raine, A., Gao, Y., \& Schug, R. (2018). The mediating role of emotional intelligence on the autonomic functioning-psychopathy relationship. Biological Psychology, $136,136-143$.

Low, G. R., Nelson, D. B., et al. (2006). Emotional intelligence and college success: A research-based assessment and intervention model. Center for Education Development and Evaluation Research (CEDER), Kingsville, TX, USA.

MacCann, C., Jiang, Y., Brown, L. E., Double, K. S., Bucich, M., \& Minbashian, A. (2020). Emotional intelligence predicts academic performance: A meta-analysis. Psychological Bulletin, 146(2), 150-186.

Mayer, J. D., Salovey, P., \& Caruso, D. R. (2000). Models of emotional intelligence.

Mayer, J. D., Salovey, P., \& Caruso, D. R. (2004). Target articles: Emotional intelligence: Theory, findings, and implications. Psychological Inquiry, 15(3), 197-215.

Memon, M. A., Ting, H., Cheah, J.-H., Thurasamy, R., Chuah, F., \& Cham, T. H. (2018). Mediation analysis issues and recommendations. Journal of Applied Structural Equation Modeling, 2(1), 1-9.

Motowildo, S. J., Borman, W. C., \& Schmit, M. J. (1997). A theory of individual differences in task and contextual performance. Human Performance, 10(2), 71-83.

Niehoff, B. P., \& Moorman, R. H. (1993). Justice as a mediator of the relationship between methods of monitoring and organizational citizenship behavior. Academy of Management Journal, 36(3), 527-556.

Nowakowski, J. M., \& Conlon, D. E. (2005). Organizational justice: Looking back, looking forward. International Journal of Conflict Management, 16(1), 4-29.

Nunnally, J. C. (1994). Psychometric theory. New York: McGraw-Hill.

Organ, D. W. (1988). Organizational citizenship behavior: The good soldier syndrome. Lexington Books/DC Heath and Com.

Ouyang, Z., Sang, J., Li, P., \& Peng, J. (2015). Organizational justice and job insecurity as mediators of the effect of emotional intelligence on job satisfaction: A study from china. Personality and Individual Differences, 76, 147-152.

Patten, M. L., \& Newhart, M. (2017). Understanding research methods: An overview of the essentials. Taylor \& Francis.

Preacher, K. J., \& Hayes, A. F. (2004). Spss and sas procedures for estimating indirect effects in simple mediation models. Behavior Research Methods, Instruments, 8 
Computers, 36(4), 717-731.

Salovey, P., \& Mayer, J. D. (1990). Emotional intelligence. Imagination, Cognition and Personality, 9(3), 185-211.

Schulze, R., \& Roberts, R. D. (2005). Emotional intelligence: An international handbook. Hogrefe Publishing.

Schutte, N. S., Malouff, J. M., Hall, L. E., Haggerty, D. J., Cooper, J. T., Golden, C. J., \& Dornheim, L. (1998). Development and validation of a measure of emotional intelligence. Personality and Individual Differences, 25(2), 167-177.

Serrat, O. (2017). Understanding and developing emotional intelligence. Springer.

Sternberg, R. J., Ruzgis, P., et al. (1994). Personality and intelligence. Cambridge University Press.

Yean, T. F., et al. (2016). Organizational justice: A conceptual discussion. Procedia-Social and Behavioral Sciences, 219, 798-803. 